\title{
Assessing the Effectiveness of Waste Minimization Methods in Solid Waste Reduction at the Source by Manufacturing Firms in Malaysia
}

\author{
Shadi Kafi Mallak, Mohd Bakri Ishak ${ }^{1 *}$, Mohamad Roslan Mohamad Kasim², \\ Mohd Armi Abu Samah ${ }^{3}$ \\ 'Department of Environmental Management, Faculty of Environmental Studies, Universiti Putra Malaysia, Malaysia \\ ${ }^{2}$ Department of Forest Management, Faculty of Forestry, Universiti Putra Malaysia, Malaysia \\ ${ }^{3}$ Kulliyyah of Science, International Islamic University Malaysia, 25200 Kuantan Pahang, Malaysia
}

Received: December 17, 2014

Accepted: February 18, 2015

\begin{abstract}
Manufacturing industries in Malaysia play a fundamental role in economic growth and enhancing the population's standard of living. However, a huge quantity of industrial wastes is generated daily, exacerbating landfill disposal issues. Waste minimization as the most sustainable approach of waste handling contributes to a significant reduction of waste. In Malaysia, practicing waste minimization by manufacturing firms is not very common. Thus, this study attempted to determine the most commonly practiced methods of minimization by manufacturing firms in Malaysia. Also, the effectiveness of each method in waste reduction was explored. Data were collected through survey and analyzed through the quantitative and qualitative approaches from 214 manufacturing firms that cover small, medium, and large sizes with a $67.5 \%$ response rate. The questionnaire was developed based on the review of literature and is validated by a panel of experts. Paired sample T-test was used to compare the solid waste generation one year before and one year after practicing methods. Spearman Rho Correlation and multiple linear regression analysis were used to explore the relationships of methods and their significant contribution in waste reduction. Findings revealed that waste generation was significantly different after practicing waste minimization methods $(\mathrm{p}<0.05)$. With respect to the methods correlation and effectiveness in waste reduction, all waste minimization methods have a significant and positive correlation with waste reduction $(\mathrm{p}<0.05)$. Methods include segregation of wastes, on-site reuse and recycle, improved housekeeping, and equipment modification - all of which were found to be effective in waste reduction for Malaysian manufacturing firms $(\mathrm{p}<0.05)$.
\end{abstract}

Keywords: solid waste generation, waste minimization, manufacturing firms, minimization methods effectiveness

\section{Scenario of Waste Minimization in Malaysia}

Malaysia has aspired to be an industrialized country by 2020 [1] while manufacturing industries have tried to enhance the nation's economic growth for four decades [2].

*e-mail: albakriy@yahoo.co.uk
In line with the vision 2020 and industrial development, the level of recycling should increase up to $22 \%$ [3]. It was reported that solid waste management has a steady development but the current waste management system in Malaysia is landfill disposal, and just $5 \%$ of wastes have been recycled $[4,5]$. However, it was estimated that the recycling rate in Japan was about $40 \%$, and $13 \%$ in China [6]. 
In 2007 about $55 \%$ of wastes were recycled in Singapore, which was near $60 \%$ as the recycling target of 2020 [7].

In Malaysia, industries are in second place in terms of waste generation, which consisted of $25 \%$ of total waste generation [6]. According to Fariz [8], from the total solid wastes that increased $4 \%$ per year in $1998,30 \%$ of it was industrial, and in 2004 two million out of eight million tons of it was related to business entities [9, 10]. Despite providing an effective and appropriate system for managing solid wastes - including the launch of privatization in 1993 - the country still has not solved its solid waste management issues [5]. Although industrial waste management related regulations in Malaysia are based on two types of wastes: industrial solid wastes and industrial hazardous wastes [2]. However, the different parts of services dealing with solid waste management are under the responsibility of the private sector [11].

With respect to waste minimization, It was reported that practicing waste minimization by industries in Malaysia is not very common, and that just a few numbers of industries apply it as one component in the waste management hierarchy, which is not effective enough in reducing the total quantity of generated waste [12]. Waste minimization will continue as one of the challenges and it is necessary to be applied more rigorously. Due to the poor waste management system in Malaysia, disposal sites receive a mixture of industrial solid and municipal wastes such as plastic, iron, paper, food wastes, rubber, textile, metal, glass, cardboard, aluminum, and miscellaneous [4, 13, 14].

In Malaysia the absence of a regulatory framework and suitable policy in waste minimization hinder industries to control the quantity of waste arising from manufactring and efficient waste mangement $[4,15]$. Beside this, the fiscal aspects also play a fundamental role in waste minimiztiation implementation, and the absences of financial support are fundamental barriers in waste management and applying new technologies for waste reduction $[4,11]$. It was reported that there is not a specific fund that provides for industrial segments in Malaysia to reduce their wastes [15]. As stated by Agamuthu et al. lack of environmental awareness and perception toward wastes management and minimization worsens waste issues [16].

This paper highlighted the necessity of solid waste minimization at the source and its barriers as the most sustainable option in the waste management hierarchy. To address the importance of waste minimization, the differences of solid waste generation one year before and one year after practicing minimization methods were examined. Also in this study the most effective methods in waste reduction at source were explored. Findings of this study can provide a useful baseline of information and data specifically on industrial solid waste minimization at the source among manufacturing firms. These data were found to be very helpful for determining the most appropriate methods for handling.

The following hypotheses were considered, tested, and discussed in this study:

$H_{1}$ : There is no significant change in the quantity of total solid waste generation before and after waste minimization.
$H_{2}$ : There is no relationship between waste minimization methods and waste reduction.

$H_{3}$ : There is no significant effect of waste minimization methods on waste reduction.

\section{Waste Minimization Methodologies}

Much of the literature argues about the waste minimization strategies and methodologies [17-20]. Although the efficiency of methods can be influenced by size and types of industrial activities, all techniques can be helpful in achieving sustainable waste management $[17,21]$.

Waste segregation at source, reusing recycling materials, and practicing good housekeeping was introduced by Rao and Prabhakar [20] as methods for waste minimization. Similarly, Vigneswaran et al. [21] and Babu et al. [17] have implied improved housekeeping, changing technological processes, changing product, changing input material, and recovering by-products. Furthermore, methods such as inventory control, raw material modification, product modification, production process modification, changing packaging, and equipment modification were introduced by Clelland et al. [22]. The following methods are the most common methods for reduction and control of waste generation and minimization at source suggested by previous studies:

\section{Segregation of Wastes}

Segregation of wastes at source was introduced as an effective method to improve other options of minimization and management [23]. This practice was considered useful for preventing reusable material from being polluted by other types of hazardous wastes, and helpful for reducing wastes sent for disposal. Also, by separating the wet and dry wastes the moisture content will be reduced. By separating the wastes at source properly, time and effort for handling will be reduced $[23,24]$.

\section{Improve Housekeeping}

Good housekeeping plays an important role in source control that leads to waste reduction. Good housekeeping includes activities associated with providing raw materials with the suitable volume and quantity, and proper inventory of the material $[20,25]$. It also controls the accuracy and efficiency of process performance [19].

\section{Product Modification and Redesign Packaging}

Product modification can be achieved by modifying the redesign of products and modified packaging for the purpose of reducing the waste generation at final process. Also, it includes replacing the recyclable products with non-recyclable ones [19, 22].

\section{Product Design and Reformulation}

This method includes reformulation and modification of old products into products that generate less waste. 


\section{Product Substitution}

This method includes the replacement of products with less-polluting ones. For instance, using starch-based materials instead of petroleum-based.

\section{Changing Input Material (Raw Material Modification)}

This method includes changing or modifying the raw material before it enters process production [22].

\section{Changing Process Technology}

Technology modification was known as the most effective method in minimizing the quantity of wastes at source. Modifying and changing the process technology as one category of technology modification is defined as changing and modifying the process technology into more efficient with low-waste generation; also, it includes modifying the process by improving reactions between parameters [22, 25].

\section{Equipment Modification}

Another category of technology modification is equipment change and modification [25]. This method was introduced as one of the most desirable means for reducing waste [26].

\section{On-Site Recycle/Reuse}

Many industries reuse and recycle directly waste materials for use as raw materials in their production process [27]. On-site reuse and recycling includes recycling and reusing at the same place where the activity began (while off-site reuse and recycling is opposite to on-site activity). On-site reuse is defined as "the re-employment of products or materials, in their original form or in new applications, with refurbishing to original or new specifications as required at the same place of the activity." On-site recycling is "the extension of the effective life span of renewable and non-renewable resources through changes to processes or practices and the addition of energy inputs at the same place of the activity" [19].

\section{Materials and Methods}

We used both secondary and primary data in this study. As revealed in Fig. 1, the parallel mixed method approach was applied as the research design in order to strike a balance between the limitations and biases of adopting one method. In environmental study, the mixed method is commonly used in waste management research [28-30]. The results of interview analysis were used as a supplement for the results from quantitative analysis and used for the discussion part

\section{Sampling and Data Collection}

Indeed, the survey was conducted among the stakeholders involved in solid waste management of manufacturing firms in one of the well-known industrial states in Malaysia. The study used both a structured questionnaire and semi-structured interview to attain research hypotheses. It contained different types of manufacturing firms, which necessitates the use of simple random sampling method. In this method of sampling, each area will have a chance to be selected with different types and numbers of firms [31]. Approximately 1800 manufacturing firms were situated in this area and the calculated sample size of the study is 317 (95\% confidence level) based on Cochran (1977)'s formula [32]. However, the collected and completed data was 214 respondents, which constitutes a $67.50 \%$ response rate, which is sufficient for conducting statistical analysis [33, 34].

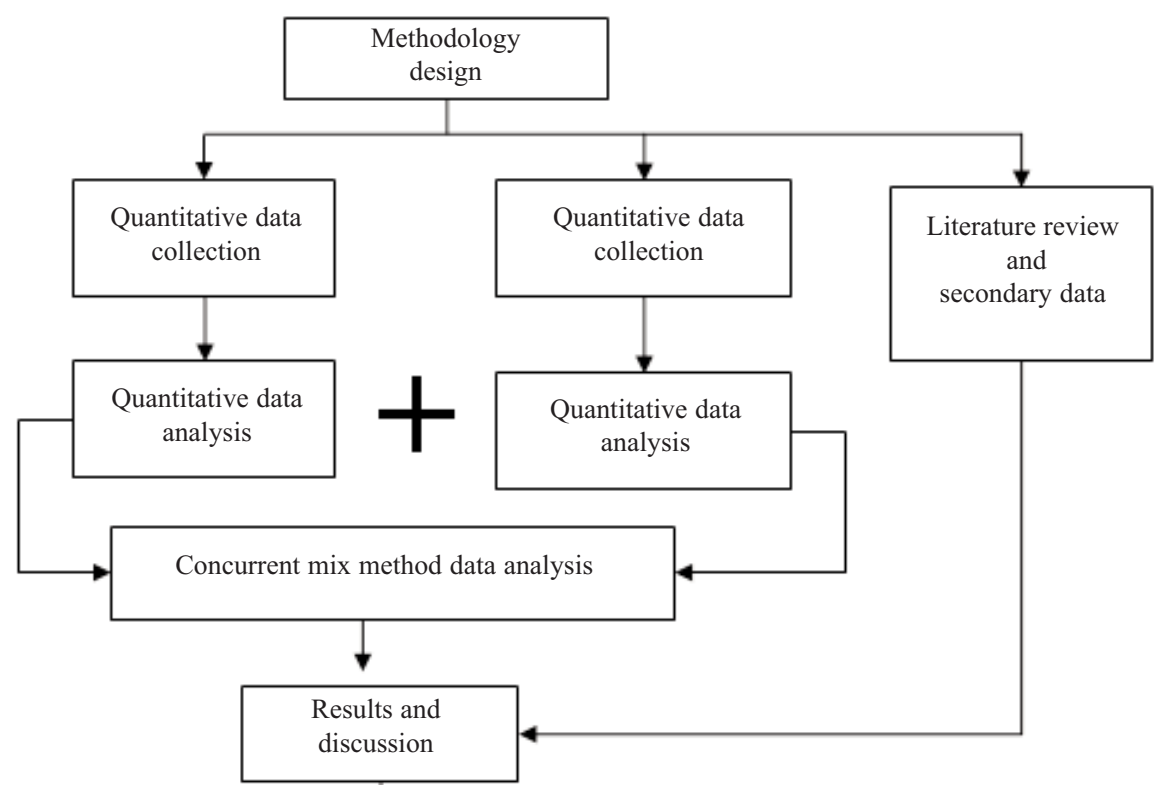

Fig. 1. Research methodology. 


\section{Data Analyses}

The quantitative data was analyzed using IBM-SPSS 20 software, and the statistical techniques that were used include descriptive statistics, paired sample T-test, Spearman correlation, and multiple regression analysis. Also, exploratory data analysis was done at an earlier stage to provide evidence for selecting the type of inferential statistics such as normality and multi-collinearity. For instrument validity in this research, content validity was employed as this method is sufficient to measure the goodness of an instrument. It certifies that the items in the survey are sufficient, appropriate, and demonstrative enough to be verified by a panel of judges [31].

\section{Paired Sample T-test}

The first section of the questionnaire was designed to gather the information with respect to the quantity of solid waste generation (tons/year) before and after practicing waste minimization. In this study a paired sample T-test was used to compare the mean score of total waste generation before and after practicing waste minimization.

\section{Spearman Correlation and Multiple Linear Regression}

The other part of the questionnaire was related to waste minimization as applied by industries. In this part respondents were asked to provide the frequency of waste minimization practicing. Five-point Likert scales were used to provide several frequency options for minimization methods practicing as below statements, which were modified from Afroz et al. [35], Begum et al. [36], and Vagias [37] as:

$0=$ not practiced at all

$1=$ seldom practices

$2=$ sometimes practices

$3=$ often practices

$4=$ most frequently practiced

In this part of the study, frequency analysis was first used to show the level of practicing among manufacturing firms. Secondly, correlation analysis was used to determine the relationship between the quantity of waste reduction and waste minimization methods. This was followed by multiple linear regression analysis to show the significant effects of methods in reduction of wastes.

\section{Results and Hypotheses Testing}

The inferential statistic was used to examine the earlierproposed $H_{1}, H_{2}$, and $H_{3}$. The results of the analyses are stated bellow.

\section{Difference of Waste Generation before and after Practicing Waste Minimization}

The paired sample t-test analysis results as revealed in Table 1 showed that there is a significant difference in total
Table 1. Paired sample T-test comparisons of total solid waste generation before and after practicing waste minimization methods $(\mathrm{n}=214)$.

\begin{tabular}{|c|c|c|c|c|}
\hline Variables & $\mathrm{M}$ & $\mathrm{SD}$ & $\mathrm{t}$ & Sig. \\
\hline WGB & 157.85 & 510.05 & 14.193 & 0.001 \\
\hline WGA & 105.36 & 418.63 & - & - \\
\hline
\end{tabular}

M - Mean, SD - Standard deviation, Sig. - P-value, WGB Mean of waste generation before practicing, WGA - Mean of waste generation after practicing, $\mathrm{t}$ - the statistical test was performed using $\log _{10}$ transformed value of waste generation

waste generation after practicing waste minimization methods among all manufacturing firms $(\mathrm{p}<0.05)$. The mean score of total waste generation before practicing waste minimization $(M=157)$ was greater than the mean score of total waste generation after practicing waste minimization $(\mathrm{M}=105)$. Also Fig. 2 depicts the mean of waste generation before and after waste minimization practicing among different size of firms.

The mean of waste generation for each type of solid wastes are illustrated in Fig. 3 below. Hence $H_{1}$ is rejected.

\section{Correlation and Effectiveness of Waste Minimization Methods}

Table 2 shows the results of descriptive statistic (percentage, mean, and standard deviation) regarding waste

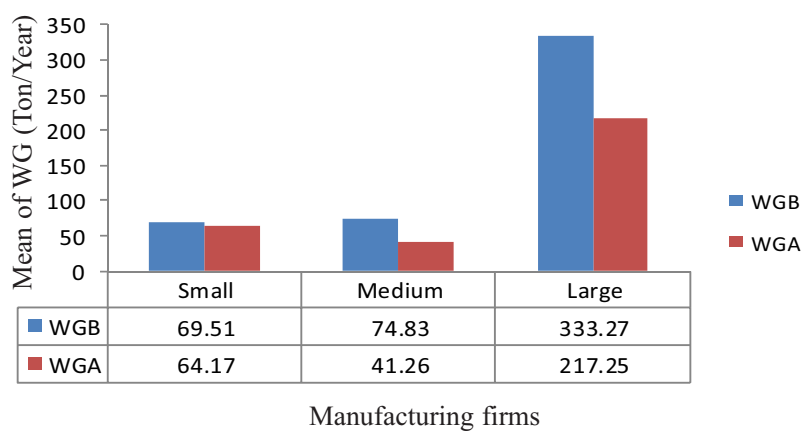

Fig. 2. Mean comparison of waste generation among firm sizes.

-WGB (Mean) $\quad$ WGA (Mean)

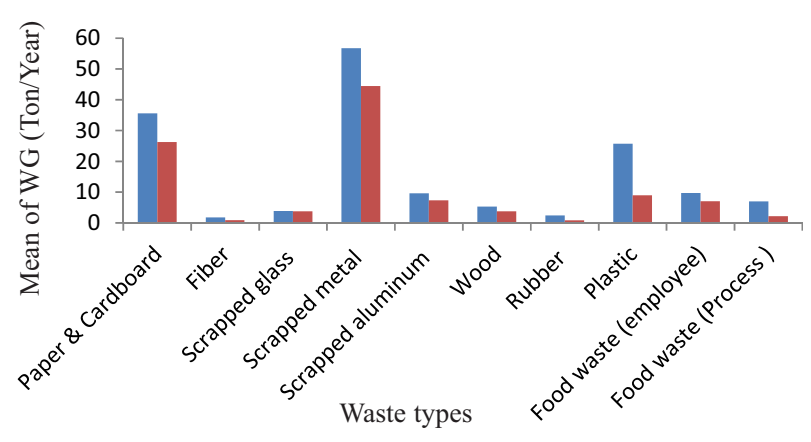

Fig. 3. Mean of waste generation for industrial solid waste. 
Table 2. Frequency, mean, and standard deviation of the solid waste minimization methods.

\begin{tabular}{|c|c|c|c|}
\hline Waste minimization methods & Frequency $(\%)$ & M & SD \\
\hline A: Improve house keeping & 63 & 2.42 & 1.377 \\
\hline B: Product modification/change & 22 & 1.36 & 0.779 \\
\hline C: Changing/modification In-put material & 15 & 1.25 & 0.705 \\
\hline D: Change/modification process technology & 26 & 1.45 & 0.906 \\
\hline E: On-site reuse /Recycle & 67 & 2.60 & 1.379 \\
\hline F: Equipment modification/change & 28 & 1.52 & 0.963 \\
\hline G: Redesign packaging & 23 & 1.41 & 0.882 \\
\hline H: Segregation of wastes & 62 & 2.37 & 1.384 \\
\hline
\end{tabular}

$\mathrm{M}$ - Mean of practicing methods, SD - Standard deviation

Table 3. Spearman correlation between waste minimization methods and waste reduction.

\begin{tabular}{|l|c|}
\hline \multicolumn{1}{|c|}{ Variables } & $\mathrm{Y}(\mathrm{WR})$ \\
\hline X1 (Improve housekeeping) & $0.417^{* *}$ \\
\hline X2 (Product modification/change) & $0.262^{* *}$ \\
\hline X3 (Changing/modification in-put material) & $0.199^{* *}$ \\
\hline X4 (Changing/modification process technology) & $0.191^{*}$ \\
\hline X5 (On-site reuse/recycle) & $0.376^{* *}$ \\
\hline X6 (Equipment modification/change) & $0.345^{* *}$ \\
\hline X7 (Redesign packaging) & $0.219^{*}$ \\
\hline X8 (Segregation of waste) & $0.424^{* *}$ \\
\hline
\end{tabular}

$* \mathrm{P}<0.05,{ }^{* *} \mathrm{P}<0.01$

WR - Waste reduction (dependent variable) minimization methods at source. Based on Table 2, approximately $67 \%$ out of 214 firms reuse and recycle waste at the source, with a total mean score of 2.60 , followed by improved housekeeping by $63 \%$ of firms with a mean score of 2.42 , and waste segregation by about $62 \%$ out of 214 firms with a total mean score of 2.37 .

Other methods include equipment modification, practiced by $28 \%$ of firms; changing (modifying) process technology, practiced by $26 \%$ of firms; package redesign by $23 \%$ of firms; product modification by $22 \%$ of 214 firms; and changing input material as practiced by $15 \%$ of firms, with a mean score ranging from 1.25 to 1.52 .

As depicted in Table 3, Spearman's rank correlation analysis has shown that there was a significant positive relationship between improved housekeeping $(\mathrm{r}=0.417$, $\mathrm{p}=0.001)$, product modification/change $(\mathrm{r}=0.262, \mathrm{p}=0.001)$, changing/modification input material $(\mathrm{r}=0.199, \mathrm{p}=0.003)$,

Table 4. Multiple linear regression between independent variables (methods) and waste reduction (dependent variable).

\begin{tabular}{|c|c|c|c|c|c|c|c|}
\hline \multirow{2}{*}{ Model } & \multicolumn{2}{|c|}{ Unstandardized coefficients } & \multicolumn{2}{|c|}{ Standardized coefficients } & \multicolumn{3}{|c|}{ Collinearity statistic } \\
\hline & $\mathrm{B}$ & Std. Error & Beta & $\mathrm{t}$ & Sig. & Tolerance & VIF \\
\hline Constant & 0.312 & 0.144 & - & 2.167 & 0.031 & - & - \\
\hline $\mathrm{A}$ & 0.082 & 0.030 & 0.146 & 2.090 & 0.038 & 0.659 & 1.518 \\
\hline B & 0.104 & 0.062 & 0.105 & 1.674 & 0.096 & 0.819 & 1.221 \\
\hline $\mathrm{C}$ & 0.008 & 0.071 & 0.007 & 0.110 & 0.913 & 0.757 & 1.321 \\
\hline $\mathrm{D}$ & 0.044 & 0.052 & 0.051 & 0.835 & 0.405 & 0.845 & 1.183 \\
\hline $\mathrm{E}$ & 0.115 & 0.035 & 0.205 & 3.315 & 0.001 & 0.839 & 1.192 \\
\hline $\mathrm{F}$ & 0.141 & 0.050 & 0.176 & 2.798 & 0.006 & 0.810 & 1.235 \\
\hline $\mathrm{G}$ & 0.042 & 0.055 & 0.047 & 0.759 & 0.448 & 0.822 & 1.216 \\
\hline $\mathrm{H}$ & 0.124 & 0.038 & 0.223 & 3.303 & 0.001 & 0.705 & 1.419 \\
\hline
\end{tabular}

A - Improve housekeeping, B - Product modification (change), C - Change (modification) in-put material, D - Change (modification) process technology, E - On-site Reuse/Recycle, F - Equipment modification (change), G - Redesign packaging, H - Segregation of waste.

Sig. - P-value. 
changing/modifying process technology $(\mathrm{r}=0.191$, $\mathrm{p}=0.005)$, on-site reuse/recycling $(\mathrm{r}=0.376, \mathrm{p}=0.001)$, equipment modification/change $(\mathrm{r}=0.345, \mathrm{p}=0.001)$, redesign packaging $(\mathrm{r}=0.219, \mathrm{p}=0.001)$, and segregation of waste $(r=0.424, p=0.001)$ and waste reduction. This indicated that all methods of waste minimization have significant and positive correlations to reducing the quantity of waste. So $\mathrm{H}_{2}$ also is rejected.

Multiple linear regression analysis in Table 4 presents the regression coefficients predictor variables in relation to outcome variables (waste reduction). The summary ANOVA have shown that the regression model consists of eight independent variables, namely A, B, C, D, E, F, G, and $\mathrm{H}$ are significant $F(8,205)=13.428, p<0.05$. This means the regression equation is not equal to zero; therefore the model fits the data (for summary ANOVA table refer to Appendix 1). The regression analysis show that method $A(\beta=0.146$, $\mathrm{t}=2.090, \mathrm{p}=0.038)$, method $\mathrm{E}(\beta=0.205, \mathrm{t}=3.315, \mathrm{p}=0.001)$, method $F(\beta=0.176, t=2.798, p=0.006)$, and method $H$ ( $\beta=0.223, t=3.303, p=0.001)$ significantly contributed to waste reduction. Moreover, there is no multicolinearity as the variance inflation factor (VIF) ranged from 1.183 to 1.518 , which is below the threshold of 10 [38]. Hence the results showed that $\mathrm{H}_{3}$ is rejected.

\section{Discussions}

\section{Comparison of Industrial Solid Waste Generation before and after Practicing Waste Minimization}

As stated earlier, the results from Table 1 show that there is a significant difference in WGB and WGA among manufacturing industries $(\mathrm{p}<0.05)$. Therefore, the researcher perceived that by practicing waste minimization solid waste generation decreased significantly. Despite the significant reduction, the interview findings revealed that the scrapped metal, plastic wastes, and wood wastes created more handling challenges. It was further emphasized that scrapped metal and plastic were generated in the large quantity within production process and in many cases it cannot be reused as raw material into production process. Arguably, numerous studies mentioned that the classification and identification of the type of industrial solid waste is helpful to determine the appropriate methods for their handling [17, 21, 39].

\section{Effectiveness of Waste Minimization Methods}

Based on the Spearmen rank correlation analysis regarding the relationship between waste minimization methods and waste reduction, the results show that there was a significant positive relationship between waste minimization methods and quantity of waste reduction $(\mathrm{p}<0.05)$. This finding is in line with Hopper et al. [25], Staniskis and Stasiskiene [40], Clelland et al. [22], Babu et al. [17], and Simpson [41].

Fig. 4 below illustrates all methods of waste minimization in this study with both significant $(\mathrm{p}<0.05)$ and no significant contribution $(\mathrm{p}>0.05)$ in waste reduction.

In a similar vein, the multiple linear regressions revealed that segregation of wastes $(\beta=0.223)$, on-site recycling $(\beta=0.205)$, equipment modification $(\beta=0.176)$, and improved housekeeping $(\beta=0.146)$ significantly affect waste reduction $(\mathrm{p}<0.05)$.

Certainly most of the waste minimization methods that have a significant effect on waste reduction were highly practiced by manufacturing firms. As discussed earlier in the descriptive part (Table 2), segregation of
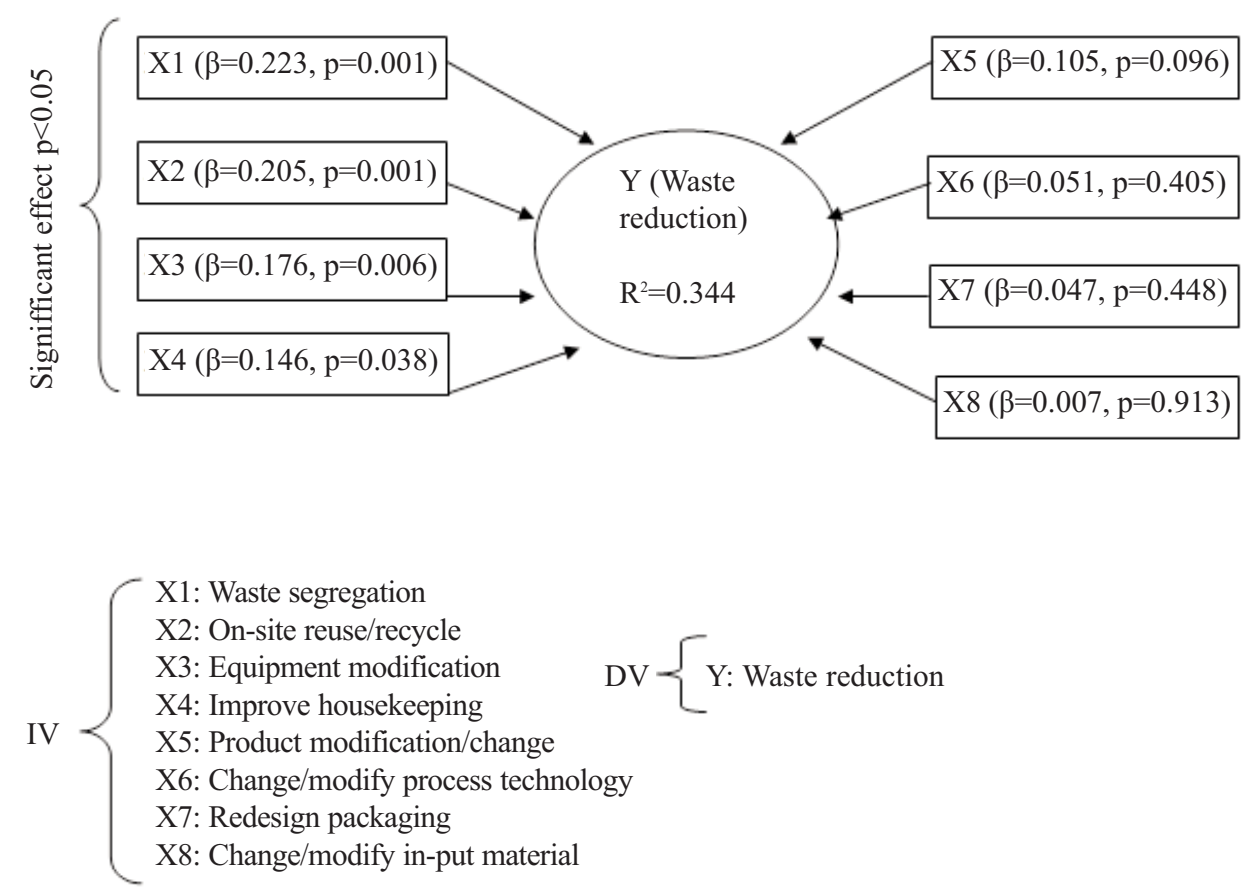

Fig. 4. Contribution of waste minimization methods in waste reduction. 
waste was practiced by $62 \%(\mathrm{M}=2.37)$ of manufacturing firms, on-site recycling and reuse was practiced by $67 \%$ $(\mathrm{M}=2.60)$ of firms, and improved housekeeping was practiced by $63 \%(M=2.42)$ of firms. However, despite significant contributions of equipment modification, the level of its practice is low as a descriptive analysis revealed that only $28 \%$ of firms use this method with the mean score of 1.52 .

This finding is consistent with Phillips et al. [42], that waste reduction and cost savings were achieved through significantly improved housekeeping. Rao and Prabhakar [22] also have explored segregation of wastes and good housekeeping as the most effective methods in their factory. Furthermore, Staniskis and Stasiskiene [40] revealed that $52 \%$ of wastes decreased by improved housekeeping. Also, Simpson's [41] findings indicated that $55 \%$ of wastes were reduced by waste segregation.

In terms of on-site reuse and recycling the findings of Staniskis and Stasiskiene [40] implied that the largest quantity of wastes, about $75 \%$, decreased by on-site recycling. Also Begum et al. [18] have determined that on-site reuse and recycling plays the most significant role in waste reduction in his study. Findings of Musee et al. [43] and Khan and $\mathrm{Kr}$ Ghoshal [26] also supported the effectiveness of the equipment modification method as they have introduced it as a method with a high impact on controlling waste.

Based on the above arguments, we deduced that enhancing the level of practicing the above-mentioned methods in the short term can serve the purpose of practicing minimization efficiently as the most desirable option in the waste management hierarchy, especially equipment modification. However, methods such as product modification $(\beta=0.105)$, change/modification in-put material $(\beta=0.007)$, and change/modification process technology $(\beta=0.051)$ and redesign packaging $(\beta=0.047)$ did not contribute significantly to waste reduction among manufacturing firms ( $p>0.05$ ). In contrast, Clelland et al. [22] found methods including production process modification and input material modification to have more application among firms in his study. Similarly, these two methods were stressed as the most usable methods in the Raouf and Jafarzadeh study [44]. Also, Staniskis and Stasiskiene [40] have explored about $25 \%$ and $52 \%$ of wastes reduced respectively by technology modification and process modification among different types of industries. And Hopper et al. [25] introduced methods dealing with technology, process, and equipment modification as the most effective methods in reducing the waste arising at source. Two methods, including change input material and process modification, were introduced by Raouf and Jafarzadeh [44] as the most applicable methods in waste minimization. Furthermore, the above-mentioned methods were less practiced as discussed earlier in the descriptive part (Table 2). Despite the results from some other studies, in this study these methods did not significantly decrease the quantity of wastes. Therefore, identifying an acceptable way of implementing them could improve the efficiency and level of practicing as a long-term strategy. However, as highlighted by Vigneswaran et al. [21] and Redmond et al. [45], the effectiveness of each method can be different based on the type and size of the industry. In more in-depth analysis, the interview result also revealed that elements such as lack of time, manpower, and awareness were stressed among the respondents as one of the main reasons for not practicing as much waste minimization, especially segregation of wastes at the source. These findings were consistent with findings of Tonglet et al. [46] and Pongrácz [47].

Moreover, interviewees stated that methods dealing with technology are costly; therefore, some of the manufacturing firms prefer to follow the old technologies. It also revealed that some firms prefer to pay for disposal costs instead of paying for modifying and applying new technologies. This finding also is supported by Ilomäki and Melanen [48], as they have revealed that applying new technologies required huge investments by small- and medium-sized firms, which subsequently have economic consequences in relation to cost and benefit analysis. For this reason Goh [49] cautioned that old production processes are a challenge for small- and medium-sized industries for managing waste.

\section{Conclusions}

Generally, total solid waste generation has significantly decreased among manufacturing firms in Malaysia in the study area after practicing waste minimization methods, but it cannot be claimed that the quantity of waste reduction is good enough and in line with the vision for 2020.

This can bring more attention to waste reduction at the source from disposal and recycling activities. As stated by Desa et al. [13] and Moh and Abd Manaf [6], the recycling level in Malaysia (5\%) is still not sufficient to meet the 2020 target, which indicates that a huge quantity of waste will still be generated for disposal. Therefore, in the current situation source reduction, which is located at a higher level in the waste management hierarchy, compared to disposal and recycling will play a fundamental role in minimizing the quantity of wastes which send to landfill disposal.

Based on some barriers revealed earlier by interviewees it can be realized that by providing consultation from researchers and academic expertise, the effectiveness and level of practicing of these methods can be improved. Furthermore, manufacturing firms should be supported by a suitable and applicable consultation, workshops, and seminars to raise the awareness of employees and help them recognize waste minimization opportunities based on their activities. Manufacturing firms with the assistance of related solid waste management organizations should modify old technologies that are responsible for more waste generation and to ensure technologies applied by manufacturing firms are clean, generate low waste, and are environmentally friendly at the production process. Also, equipment and machine maintenance should be checked for their efficiency control. 


\section{APPENDIX 1}

Model summary of multiple linear regression analysis for waste minimization methods.

\begin{tabular}{|c|c|c|c|c|}
\hline Model & $\mathrm{R}$ & $\mathrm{R}^{2}$ & Adjusted $\mathrm{R}^{2}$ & $\begin{array}{c}\text { Std. Error of } \\
\text { the estimate }\end{array}$ \\
\hline 1 & $0.586^{\mathrm{a}}$ & 0.344 & 0.318 & 0.637 \\
\hline
\end{tabular}

Table of ANOVA for multiple linear regression.

\begin{tabular}{|l|c|c|c|c|c|}
\hline \multicolumn{1}{|c|}{ Model } & SS & Df & MS & F & Sig. \\
\hline Regression & 43.724 & 8 & 5.465 & 13.428 & $0.000^{\mathrm{a}}$ \\
\hline Residual & 83.437 & 205 & 0.407 & - & - \\
\hline Total & 127.161 & 213 & - & - & - \\
\hline
\end{tabular}

${ }^{\text {a }}$ Predictors - (Constant), H, D, E, B, G, F, C, A

Normal P-P Plot of Regression Standardized Residual Dependent Variable: TDWGC

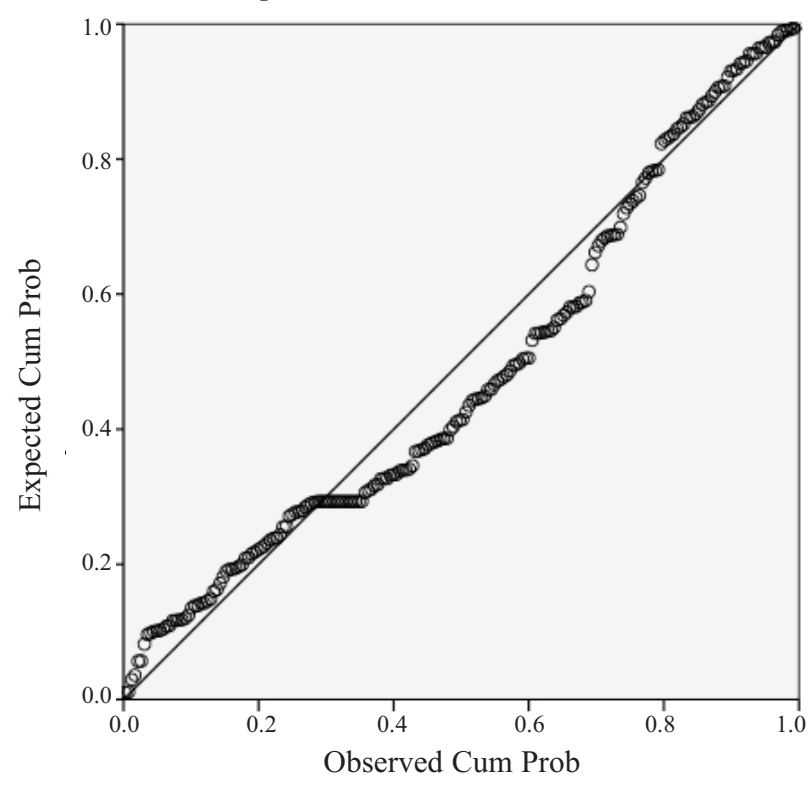

\section{References}

1. HASSAN M. N., AFROZ R., MOHAMED A. F., AWANG $\mathrm{M}$. Economic instruments for managing industrial waste in Malaysia. Malaysian Journal of Environmental Management, 6, 87, 2005.

2. MOHAMED F. Institute for The Environment and Development (LESTARI) Universiti Kebangsaan Malaysia. 3R Policies for Southeast and East Asia, 53, 2009.

3. MANAF L. A., SAMAH M. A. A., ZUKKI N. I. M. Municipal solid waste management in Malaysia: Practices and challenges. Waste Manage. 29, (11), 2902, 2009.

4. AGAMUTHU P., FAUZIAH S. Challenges and issues in moving towards sustainable landfilling in a transitory country-Malaysia. Waste Manage. Res. 29, (1), 13, 2011. doi: 10.1177/0734242X10383080
5. SAMAH M. A. A., MANAF L. A., AHSAN A., SULAIMAN W. N. A., AGAMUTHU P., D'SILVA J. L. Household solid waste composition in Balakong City, Malaysia: trend and management. Pol. J. Environ. Stud., 22, (6), 1807, 2013.

6. MOH Y. C., ABD MANAF L. Overview of household solid waste recycling policy status and challenges in Malaysia. Resour. Conserv. Recy. 82, 50, 2014.

7. KOJIMA M., DAMANHURI E. 3R Policies for Southeast and East Asia. ERIA Research Project Report (10), 2009.

8. FARIZ M. Infrastructure for Sustainable Industrial Wastes Recovery in Malaysia Paper presented at the Blueprints for Sustainable Infrastructure Conference, Auckland, NZ, 2008.

9. AGAMUTHU P., FAUZIAH S. H., SIMON C. Toward efficient waste management in a developing countries (Malaysia)-the dilemma. Philadelphia, USA, 2004.

10. EA. Perak-Solid Waste Management Plan (P-SWMP), EASWMC, EU-Asia Sustainable Waste Management Cycle, 2009.

11. SHEKDAR A. V. Sustainable solid waste management: an integrated approach for Asian countries. Waste Manage. 29, (4), 1438, 2009.

12. MHLG. National Strategic Plan for Solid Waste management Malaysia Retrieved from: http://www.kpkt.gov.my/jpspn_en_2013, 2013.

13. DESA A., KADIR N. B. Y. A., YUSOOFF F. A Study on the Knowledge, Attitudes, Awareness Status and Behaviour Concerning Solid Waste Management. Procedia-Social and Behavioral Sciences, 18, 643, 2011. doi: 10.1016/j.sbspro.2011.05.095

14. SAEED M. O., HASSAN M. N., MUJEeBU M. A. Assessment of municipal solid waste generation and recyclable materials potential in Kuala Lumpur, Malaysia. Waste Manage. 29, (7), 2209, 2009.

15. MHLG. National Strategic Plan for Solid Waste Management Malaysia, http://www.kpkt.gov.my/jpspn_en_2013 2013.

16. AGAMUTHU P., FAUZIAH S., KHIDZIR K., AIZA A. N. Sustainable waste management-Asian perspectives. Paper presented at the Proceedings of the International Conference on Sustainable Solid Waste Management. 5, 2007.

17. BABU B. R., BHANU S. U., MEERA K. S. Waste minimization in electroplating industries: a review. J.Environ. Sci. Heal. C 27, (3), 155, 2009. doi: 10.1080/10590500903124158

18. BEGUM R. A., SIWAR C., PEREIRA J. J., JAAFAR A. H. Implementation of waste management and minimisation in the construction industry of Malaysia. Resour. Conserv. Recy. 51, (1), 190, 2007.

19. CANADA. Pollution Prevention Planning Handbook. Retrieved from https://www.ec.gc.ca, 2013.

20. RAO L. N., PRABHAKAR G. Waste Minimization in the Chemical Process. 2013.

21. VIGNESWARAN S., JEGATHEESAN V., VISVANATHAN C. Industrial waste minimization initiatives in Thailand: concepts, examples and pilot scale trials. Journal of Cleaner Production, 7, (1), 43, 1999.

22. CLELLAND I. J., DEAN T. J., DOUGLAS T. J. Stepping towards sustainable business: An evaluation of waste minimization practices in US manufacturing. Interfaces, 30, (3), 107, 2000.

23. AJA O. C., AL-KAYIEM H. H. Review of municipal solid waste management options in Malaysia, with an emphasis on sustainable waste-to-energy options. Journal of Material Cycles and Waste Management, 1-18, 2013.

24. EPA. Waste minimization an Environmental good practice guide for industry, 2001 
25. HOPPER J. R., YAWS C. L., HO T., VICHAILAK M Waste minimization by process modification. Waste Manage. 13, (1), 3, 1993.

26. KHAN F. I., KR GHOSHAL A. Removal of volatile organic compounds from polluted air. J. Loss Prevent. Proc. 13, (6), 527, 2000

27. MBULIGWE S. E., KASEVA M. E. Assessment of industrial solid waste management and resource recovery practices in Tanzania. Resour. Conserv. Recy. 47, (3), 260, 2006.

28. CRESWELL J. W. Research design: Qualitative, quantitative, and mixed methods approaches Thousand Oaks: Sage Publicatons, 2003

29. CRESWELL J. W. Research design: Qualitative, quantitative, and mixed methods approaches: SAGE Publications, Incorporated, 2008.

30. MORRISSEY A., BROWNE J. Waste management models and their application to sustainable waste management. Waste Manage. 24, (3), 297, 2004.

31. SEKARAN U. Research methods for business: A skill building approach: John Wiley and Sons. 2006.

32. COCHRAN W. G. Sampling techniques. New York: John Wiley \& Sons. 1977.

33. BARUCH Y., HOLTOM B. C. Survey response rate levels and trends in organizational research. Hum. Relat., 61, (8), 1139, 2008.

34. REA L. M., PARKER R. A. Designing and conducting survey research: A comprehensive guide: John Wiley and Sons, 2012.

35. AFROZ R., HANAKI K., TUDIN R. Factors affecting waste generation: a study in a waste management program in Dhaka City, Bangladesh. Environ. Monit. Assess. 179, (14), 509, 2011.

36. BEGUM R. A., SIWAR C., PEREIRA J. J., JAAFAR A. H. Attitude and behavioral factors in waste management in the construction industry of Malaysia. Resour. Conserv. Recy. 53, (6), 321, 2009.

37. VAGIAS W. M. Likert-type scale response anchors. Clemson International Institute for Tourism and Research Development, 1, 2006.
38. HAIR J. F., BLACK W. C., BABIN B. J., ANDERSON R. E., TATHAM R. L. Multivariate Data Analysis Pearson Prentice Hall. Upper Saddle River, 2006.

39. PATWARDHANA. Industrial Solid Wastes: TERI Press. 2013.

40. STANISKIS J. K., STASISKIENE Z. Industrial waste minimization-experience from Lithuania. Waste Manage. Res. 23, (4), 282, 2005.

41. SIMPSON D. Use of supply relationships to recycle secondary materials. Int. J. Prod. Res. 48, (1), 227, 2010.

42. PHILLIPS P. S., READ A. D., GREEN A. E., BATES M. P. UK waste minimisation clubs: a contribution to sustainable waste management. Resour. Conserv. Recy. 27, (3), 217, 1999.

43. MUSEE N., LORENZEN L., ALDRICH C. Cellar waste minimization in the wine industry: a systems approach. Journal of Cleaner Production, 15, (5), 417, 2007.

44. RAOUF F. F., JAFARZADEH R. N. N. Identification and classification of industrial solid wastes in ammonia unit of Razi petrochemical complex and feasibility of waste minimization. Iranian Journal of Environmental Health Science and Engineering, 2, (4), 261, 2005.

45. REDMOND J., WALKER E., WANG C. Issues for small businesses with waste management. J. Environ. Manage. 88, (2), 275, 2008.

46. TONGLET M., PHILLIPS P. S., BATES M. P. Determining the drivers for householder pro-environmental behaviour: waste minimisation compared to recycling. Resour. Conserv. Recy. 42, (1), 27, 2004.

47. POGRÁCZ E. Through waste prevention towards corporate sustainability: analysis of the concept of waste and a review of attitudes towards waste prevention. Sustain. Dev. 17, (2), 92, 2009. doi: 10.1002/sd.402

48. ILOMÄKI M., MELANEN M. Waste minimisation in small and medium-sized enterprises - do environmental management systems help? Journal of Cleaner Production, 9, (3), 209, 2001.

49. GOH K. S. Developing hazardous waste programmes in Malaysia. Waste Manage. Res. 8, (2), 151, 1990. 
